ORIGINALARTICLE

\title{
Cost comparison of a commonly prescribed Antidepressant (Escitalopram)

\author{
Kunwar A R*
}

Address: Associate Professor, Kathmandu Medical College, Sinamangal, Kathmandu

Email*Corresponding author:arunkunwar@yahoo.com

Abstract

Introduction: Antidepressants are one of the most commonly prescribed drugs. The treatment cost of antidepressant can vary widely. The objective of this study is to find out the variation in prices of an antidepressant drug.

Method: We compared the price of an antidepressant escitalopram produced by various pharmaceutical companies (available at January 2010) and compared the cost of antidepressant therapy over six months. Escitalopram was taken as it is widely prescribed antidepressant in Nepal and it is sold under multiple trade names by different pharmaceutical companies making it ideal for this study.

Results: The cost of most expensive product over 6 months in comparison to cheapest product was more than $50 \%$ more in $10 \mathrm{mg}$ and $20 \mathrm{mg}$ categories. Elopram $10 \mathrm{mg}-$ Rs. 1263.6 and $20 \mathrm{mg}-$ Rs. $2527.2 \mathrm{vs} \mathrm{Feliz} \mathrm{S} 10 \mathrm{mg}-$ Rs. 1953 and $20 \mathrm{mg}-$ Rs. 3780. Two other products were $35 \%$ (Nexito $10 \mathrm{mg}-$ Rs. 1706) and $47 \%$ (Szetalo $10 \mathrm{mg}$ - Rs. 1861.2) more expensive than the cheapest product (Elopram 10mg - Rs. 1263.6).

Conclusion: This study concluded that there is wide price difference in the cost of an antidepressant escitalopram marketed by different pharmaceutical companies. Clinicians should be aware of the cost difference between antidepressants, which can lead to significant savings to patients and society as a whole.

Key words: Cost comparison, Antidepressant, Escitalopram

\section{INTRODUCTION}

Antidepressants are one of the most commonly prescribed drugs ${ }^{1}$. The indication for antidepressant includes major depressive disorder, generalized anxiety disorder, obsessive compulsive disorder, and intractable pain and so on. Antidepressants are often prescribed for a long period. Usual course is anywhere between 6 to 12 months and some patients may take these drugs for years. Due to this, overall cost of an antidepressant cost can be huge. Escitalopram is a selective serotonin reuptake inhibitor (SSRI) approved for the treatment of adults with major depressive disorder, generalized anxiety disorder, and social anxiety disorder ${ }^{2}$. Escitalopram is marketed since 2002 and is an active part of the older drug citalopram which has been in marketed since $1989^{3}$. Vvarious randomized control trials comparing escitalopram against other antidepressants for patients with major depressive disorder have shown probable better efficacy and acceptability especially for acute response ${ }^{[4]}$. Over this last couple of years escitalopram is increasingly being prescribed by physicians in Nepal, which has led to various pharmaceutical companies marketing this drug under different brand name. As this drug is often taken for a long period, the financial burden maybe significant to a patient and society in general. The cost may also be a factor whether patient continues to take this drug so it is important for prescribers to be aware of the cost of the drugs they prescribe. Given all other quality of a drug is same; it will probably make sense to prescribe the most cost effective drug for the aforementioned reasons.

In Nepali drug market there are multiple drug companies that are often marketing a single compound (such as escitalopram). Even though the chemical composition, strength and quality of products are similar, there is wide variation in the cost of these drugs. To see what is the cost variation of a given antidepressant we took one of the most commonly prescribed antidepressant escitalopram in Nepal (clinical experience) that is marketed by multiple pharmaceutical companies. In our knowledge this is a first such study that has looked into costing of an antidepressant in Nepal. Our aim is to find the cost variation of an antidepressant in Nepalese pharmaceutical market.

\section{METHOD}

We took one of the most commonly prescribed antidepressant that is marketed by multiple pharmaceutical companies. We only compared only one antidepressant so that we can keep all other factors constant such as physician preference, indication, side effects, chemical composition and strength (hence their influence in prescribing an antidepressant was nullified). We obtained the cost of all available brands of escitalopram from a pharmacy. We also obtained the price directly from the packaging of a product and also compared the price from two different pharmacies to see if there was a price difference between pharmacies. We also calculated what would be the cost for a typical treatment of anti depressant assuming all prescriptions of depression were prescribed for 6 months. We used the following formula to find the total cost of depression over course of treatment ( 6 monts). 
Cost of antidepressant per day $X 180$ days ( 6 months) $=$ cost of one course of anti depressant

\section{RESULT}

Table 1: Cost figures of the Escitalopram drug under various trade names along with 6 months cost comparison between different brands of Escitalopram

\begin{tabular}{|c|c|c|c|}
\hline $\begin{array}{l}\text { Drugs } \\
\text { name }\end{array}$ & $5 \mathrm{mg}$ & $10 \mathrm{mg}$ & $20 \mathrm{mg}$ \\
\hline $\begin{array}{l}\text { Elopram } \\
\text { (Magnus) }\end{array}$ & 4.47 & 7.02 & 14.04 \\
\hline $\begin{array}{l}\text { Nexito } \\
\text { (Sun) }\end{array}$ & 5.56 & 9.48 & 18.96 \\
\hline $\begin{array}{l}\text { Szetalo } \\
\text { (Pyramol) }\end{array}$ & 5.63 & 10.34 & 20.68 \\
\hline $\begin{array}{l}\text { Feliz S } \\
\text { (Torrent) }\end{array}$ & 5.94 & 10.85 & 21.7 \\
\hline $\begin{array}{l}6 \text { months ce } \\
\text { Escitalopra }\end{array}$ & $\begin{array}{l}\text { mparison be } \\
\text { Nepalese R }\end{array}$ & $\begin{array}{l}\text { veen differe } \\
\text { ees) }\end{array}$ & brands of \\
\hline $\begin{array}{l}\text { Drugs } \\
\text { name }\end{array}$ & $5 \mathrm{mg}$ & $10 \mathrm{mg}$ & $20 \mathrm{mg}$ \\
\hline $\begin{array}{l}\text { Elopram } \\
\text { (Magnus) }\end{array}$ & 804.6 & 1263.6 & 2527.2 \\
\hline $\begin{array}{l}\text { Nexito } \\
\text { (Sun) }\end{array}$ & 1000.81 & 1706.4 & 3412.8 \\
\hline $\begin{array}{l}\text { Szetalo } \\
\text { (Pyramol) }\end{array}$ & 1013.4 & 1861.2 & 3722.4 \\
\hline $\begin{array}{l}\text { Feliz S } \\
\text { (Torrent) }\end{array}$ & 1069.2 & 1953 & 3906 \\
\hline $\begin{array}{l}\text { Cost } \\
\text { Difference }\end{array}$ & 264.6 & 689.4 & 1378.8 \\
\hline $\begin{array}{l}\text { Cost } \\
\text { difference } \\
\text { assuming }\end{array}$ & $26,46,000$ & $68,94,000$ & $1,37,88,000$ \\
\hline
\end{tabular}

Above results indicate that there is wide variation in cost of escitalopram marketed by different pharmaceutical companies. In $5 \mathrm{mg}$ strength the most expensive product Feliz S from Torrent) was more than $50 \%$ expensive than the cheapest product (Elopram from Magnus), and was $35 \%$ cheaper than the next cheapest product (Nexito from Sun). Similarly difference in cost was also observed in 10 $\mathrm{mg}$ and $20 \mathrm{mg}$ category.

When comparing cost over the course of antidepressant, there was also significant cost difference between products. The cost of most expensive product over 6 months in comparison to cheapest product was more than $50 \%$ more in $10 \mathrm{mg}$ and $20 \mathrm{mg}$ categories. Elopram $10 \mathrm{mg}-$ Rs. 1263.6 and $20 \mathrm{mg}-$ Rs. 2527.2 vs Feliz S 10mg - Rs. 1953 and $20 \mathrm{mg}-$ Rs. 3780 . Two other products were $35 \%$ (Nexito $10 \mathrm{mg}$ - Rs. 1706) and $47 \%$ (Szetalo $10 \mathrm{mg}$ - Rs. 1861.2) more expensive than the cheapest product (Elopram $10 \mathrm{mg}$ - Rs. 1263.6).

\section{DISCUSSION}

Above finding clearly indicates that there is a significant cost difference between same product marketed by different pharmaceutical companies. This has a significant Kunwar: Cost comparison of a commonly prescribed Antidepressant (Escitalopram) implication for patients and society. Depression is one of the most common disorder and carries significant disability to people who suffer from it. The proper treatment is vital for the recovery. In developed countries, in any given time about $25 \%$ of the population are receiving medication for depression( $)$. In Nepal there is no clear data as how many people are receiving antidepressant. As society is becoming more aware and number of providers (psychiatrist and other physician) are increasing, the more and more people in Nepal will also be receiving antidepressants. If we assume that there are 10,000 individuals who are receiving escitalopram for various causes, the cost of prescribing cheaper brand will lead to over all saving between Rs. $44,20,000$ to $68,94,000$ for $10 \mathrm{mg}$ and at least double that amount for $20 \mathrm{mg}$.

This above cost is just for one antidepressant. If we assume similar differences exist between most of the drugs prescribed in Nepal, overall cost to our medical system could be enormous. It might be coincidental but notable that the cheapest product is marketed by Nepali pharmaceutical company, whereas all the other expensive brands are imported from India.

\section{CONCLUSION}

There is wide difference in the cost of an antidepressant, escitalopram marketed by different pharmaceutical companies. Prescribers must be aware of this price difference as choosing the most cost effective brand could save millions to consumers and society in general. In our clinical practice we have often seen patients who have stopped taking medication due to expense of medication. In this situation prescribing cheaper alternative could increase the compliance to treatment and may improve the outcome for patient too.

\section{REFERENCES}

1. Comparing Selective Serotonin Reuptake Inhibitors (SSRIs) to Tricyclic Antidepressants [Internet] c2009 [Updated 2009 Dec 7: Cited 2011 Feb 28]. Available from http://www.emedexpert.com/compare/ssris-vs-tca.shtml\#1

2. Escitalopram [Internet] c 2011 [Updated 2011 Feb 28: Cited 2011 Feb 28]. Available at http://en.wikipedia.org/ wiki/Escitalopram

3. Tomer G. Prevailing against cost-leader competitors in the pharmaceutical industry. Journal of Generic Medicines 2008;1(10): 1741-1343. Available from http:// www.generics.co.il/docs/Prevailing\%20against\%20costleade $\% 20$ competitors $\% 20$ in $\% 20$ the $\% 20$ phamaceutical $\% 20$ industrypdf

4. Cipriani A, Santilli C, Furukawa TA, Signoretti A, Nakagawa A, McGuire H, Churchill R, Barbui C. Escitalopram versus other antidepressive agents for depression. Cochrane Database of Systematic Reviews 2009, Issue 2. Art. No.: CD006532. DOI: 10.1002/ 14651858.CD006532.pub2

ACKNOWLEDGEMENT 